\title{
LIGHTWEIGHT AND QUICKLY ASSEMBLED: THE MOST ECO-EFFICIENT MODEL FOR ARCHITECTURE
}

\author{
J.C. GÓMEZ DE CÓZAR, A. GARCÍA MARTÍNEZ, I. ARIZA LÓPEZ \& M. RUIZ ALFONSEA \\ Department of Architectural Construction 1, University of Seville, Spain.
}

\begin{abstract}
For over 20 years, we have followed a line of research that seeks to propose models for architecture which minimize the environmental impact caused by both its construction as its use. We understand that, in order to reduce the environmental impact produced by current constructions, it is necessary to change the way they are designed and built.

The followed process has been firstly focused on the search for geometries constructed with adequate materiality which would provide effective architectural solutions with a minimum consumption of material (lightweight solutions). Secondly, we have experienced quick assembly and disassembly procedures (deployable mesh, modular systems, etc.) that reduced the assembly time of the proposed systems and, therefore, will minimize the impact (quick assembly/reversibility). Finally, it has been possible to relate the proposed models (lightweight, quick assembly and reversible) with tools for lifecycle assessment which allow accurately assess the environmental impact of them.

The use and development of LCA tools has allowed us to optimize the proposed models. In addition, in the described process, original parametric control tools (geometry and processes) have been used. They allow to particularize the proposed models to each case based on their possibilities of manufacture.

The way followed by several made works, which are applications of the proposed models, will be described then.

Keywords: architecture, life cycle assessment, lightweight, quick assembly, reversible, sustainability.
\end{abstract}

\section{INTRODUCTION. PROPOSED MODEL, OBJECTIVES}

In 1997, together with Professor R. García Diéguez, Professor J. C. Gómez de Cózar patented Florin System [1] as a lightweight and quick assembly prototype thought for architecture. This was presented at several international symposia $[2,3]$ and was cited in the literature of the time [4]. The system arose from the work of influential authors of the second half of the twentieth century, as Fuller [5] and, especially, Prouvé [6] and the work of British architects, N. Foster, R. Rogers, M. Hopkins and N. Grimshaw [7], who had changed how to define and construct buildings in the last decades of the twentieth century.

From the beginning, the aim was the design of a lightweight and quick assembly construction system for buildings trying to minimize the operations to perform in work to avoid excessive control of this building. Beginning from Florin System, a line of work was started whose obtained results were the construction of several buildings based on variations (radicals in some cases) of the first proposed models.

Until then, both research and works made from it raised the intuition that the proposed systems produced less environmental impact than traditional construction systems. As it is known, traditional systems produce a lot of energy consumption in both the amount of used materials and the construction/demolition of the building [8]. However, there was a lack of right scientific tools to enable proper evaluation of the above statement.

In 2010, Professor A. García Martínez published his doctoral thesis entitled Life Cycle Assessment (LCA) for the development of Environmental Declarations of Dwellings in Andalusia [9]. The methodology developed in his research allowed to perform the Life Cycle Assessment (LCA) of a particular building in its most important phases (manufacture, 
construction, demolition and final use), obtaining the environmental impact produced in different impact categories related to architecture and its means of production.

Knowledge and incorporation of the work of Professor García Martínez has allowed that, from the described parameters, the research will definitely focus on the search for new construction models for architecture (lightweight, quick assembly, reversible and recyclable) that minimize environmental impact.

Basically, the proposed construction model is characterized from the following relationships between the parameters that guide the model and the different phases discussed during the Life Cycle of a building:

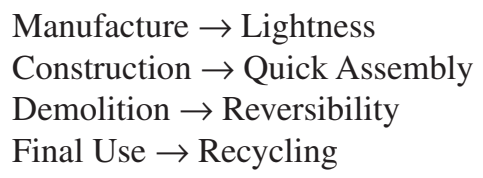

If each project is designed properly addressing the above relationships, obtained results will greatly minimize their impact during their life cycle and also will enjoy the known advantages of lightweight and quick assembly architecture.

Thus, once the general model we followed has been proposed, the main objective of this paper is presenting both the original design methodology developed and the built results which has been obtained from various interpretations of the defined model.

\section{DESIGN METHODOLOGY}

After nearly 20 years developing a research work that has produced large benefits in terms of transfer of results [10-12], the proposed design methodology and the references that have guided it have been defined from four points that are developed below.

\subsection{Searching for lightweight}

One should not forget that we are working in an architectural environment and that creativity and imagination properly guided by technology (hardware and software) must be present at all times in the process of each project definition (geometric and material) from the defined construction model [13].

It should achieve an architecture that will formally match (or exceed) the traditional or customary considered. Although we must be careful not to fall into producing heavy construction designs with the appearance of lightness. In 1995, in the book Light Constructions [14], Terence Riley, who appreciates the construction trend we follow, proposes a list of buildings which, in some cases, are built with a lightweight appearance, but are not lightweight constructions by themselves.

It must be noted that most of the work we have proposed are located in southern Spain, so the mild climate (especially in winter) allows the use of lightweight solutions which do not require envelopes with excessive thermal inertia and, therefore, too thickness. In areas where the weather is more adverse, the necessary passive conditioning strategies should be complemented by other artificial climate generated from renewable energies. For hot weather, the best built reference that can be followed is the Maison Tropicale by Jean Prouvé [6].

Thus, following P. Weijmarshausen in 2012 [15] (... The future production is not doing a lot for little but do a lot from little bit...), specific strategies that involve designing a lightweight construction must consider the following: 
- Choose the most suitable materials for every occasion.

- Suitable geometry to minimize the stresses that occur as a result of external actions, especially the wind which reach a great importance when the lighter is the solution.

- Using lightweight envelopes. Establishing the right balance between the material used for the structure and the elements of covering. Depending on the location and use of the building to be constructed, this ratio will vary from meshes (higher percentage of structure than covering) to frameworks (structure has less presence than the covering).

In each case, the decision of the type of structure to be used, its size and compatibility with the covering and the type of connections between elements, greatly influences the definition of a lightweight and easy to assembly/disassembly model.

- Increasing rigidity, both for the whole as each element, by using prestressed cables (if necessary).

\subsection{Parametrisation. Simulation, optimisation}

Twenty years ago, in the development of the Florin System, original parametric design tools were used [3].

Over time, the use of these tools has changed the concept of mobility in architecture, from a literal view of it (really mobile buildings) to a wider one, as Yona Friedman defines [16], which has to do with the ability of adaptation and variation of a design to certain conditions (parameters) which will provide a unique solution in each case, although it is constructed from the same model [17].

Once the type of geometry and possible materiality to use it is decided (depending on the context conditions and strategies for lightness established in the previous point), all geometric parameters are compiled in an original parametric tool (Grasshopper ${ }^{\mathrm{TM}}$ implemented in Rhinoceros ${ }^{\circledR}$, Dynamo for Autodesk ${ }^{\circledR}$ Revit or any other visual programming language with graphical exchange) which allows obtaining all possible configurations. By this way, the parametric process designed sets these parameters from the following simulation processes:

- Behavior against wind through virtual wind tunnel.

- Highly strength and stiffness through matrix calculation of rod elements software or finite element calculation software as appropriate.

- Energy balance under the use through the software for calculating energy flows that occur between the inside and the outside of the building.

- Sunlight and shadow production.

- Maximum solar gain. For cases where solar collection elements are incorporated into the envelope.

Once the optimization of the design is performed, the final master model is produced for fabrication (using BIM software).

\subsection{Work at workshop. Quick assembly, reversibility}

With the premises of the above two points, lightweight models can be obtained, optimized and adapted to properly use and environment. However, to ensure that the model will be a quick assembly/disassembly and/or reversible, it is necessary to establish correct relations with industry. To do this, years ago, together with Professor I. Ariza [18], we focused on 


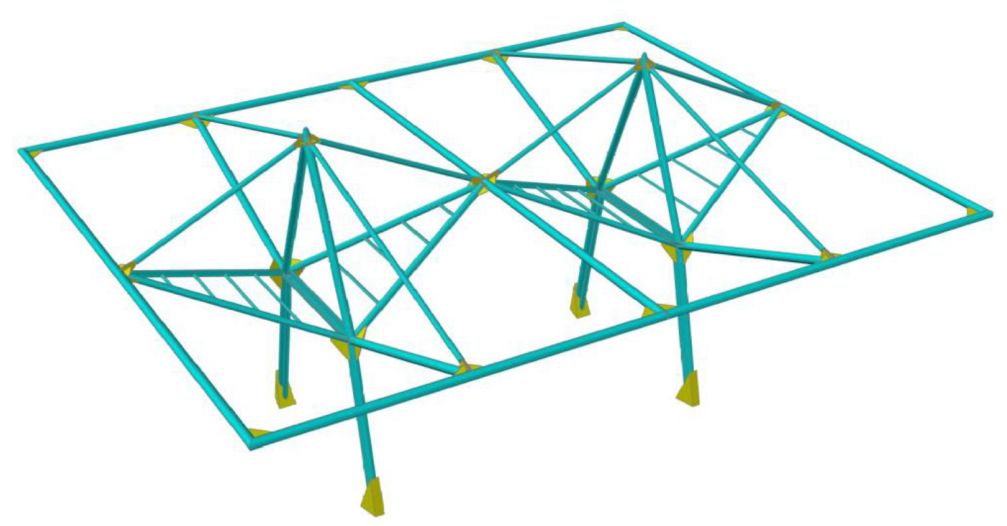

Figure 1: Example of workshop's master model with all detailed joints.

the study of constructions of ephemeral types which, because of their assembled/disassembled character, provided valuable information on building systems and, above all, types of joints employed. In turn, we have kept in contact with specialists in digital manufacturing companies who have shown us the current potential of the industry. This has to do with the possibility of manufacturing elements of increasingly size whenever it is possible its transport and site assembly. Therefore, studying and taking into account the design of pieces and size of proposed geometries and their assembly options from a proper design of connections between different systems (structure, envelope, etc.) is the fundamental task in this stage of the process.

Therefore, the fundamental strategy to produce a quick assembly and a reversible design and, thus, to get to minimize the impact and energy consumption in these phases, is based on reducing the number of items to be used (increasing its size if necessary) and designing joints to expedite the assembly process.

As will be seen below, in the followed process, there have been designed mobile joints that have led to deployable systems and fixed joints that have enabled quick assembly thanks to the minimization of the elements to be joined (Fig. 1).

\subsection{LCA as a catalyst for design}

From the results of the above three points, which have taken into account the minimization of the LCA different phases that have been considered, the LCA of the proposed model is made for checking whatever design aspect of any of its phases (materials, geometry, elements, assembly/disassembly procedures, etc.), to achieve the minimum possible environmental impact in each case.

\section{BUILT PROJECTS: CLASSIFICATION}

With the perspective that gives the time, the works that have been built from the proposed model, following the design methodology described in the preceding paragraph, have evolved from a construction point of view, from lightweight and deployable models to lightweight and quickly assembled models with parameterized geometry pieces. These ones tend to adapt 
better to the architectural discipline considering that they allow generating unique solutions that follow the same construction model, thanks to this parameterization.

The final classification of built models, according to their construction/structural system, is as follows:

- Spatial meshes of deployable bars.

- Frameworks with flexible coverings (tensioned membranes).

- Frameworks/Meshes with rigid coverings.

\subsection{Deployable and quick assembly spatial meshes}

Florin system was widely described in MARAS 2000 [3]. Based on a two-layered mesh of rhombuses and scissors connected by diagonals, it allows the possibility of constructing planar geometries, with single and double curvature (sinclastic and anticlastic). The whole system was defined from an original parametric process which fixed the geometry and predicted the structural behavior.

It was first used in 2003 to build a heated pool in Gines (Seville, Spain) [12] of $20.00 \times$ $30.00 \mathrm{~m}^{2}$ size on ground level (Fig. 2). It generates a very simple set of elements based on trian-
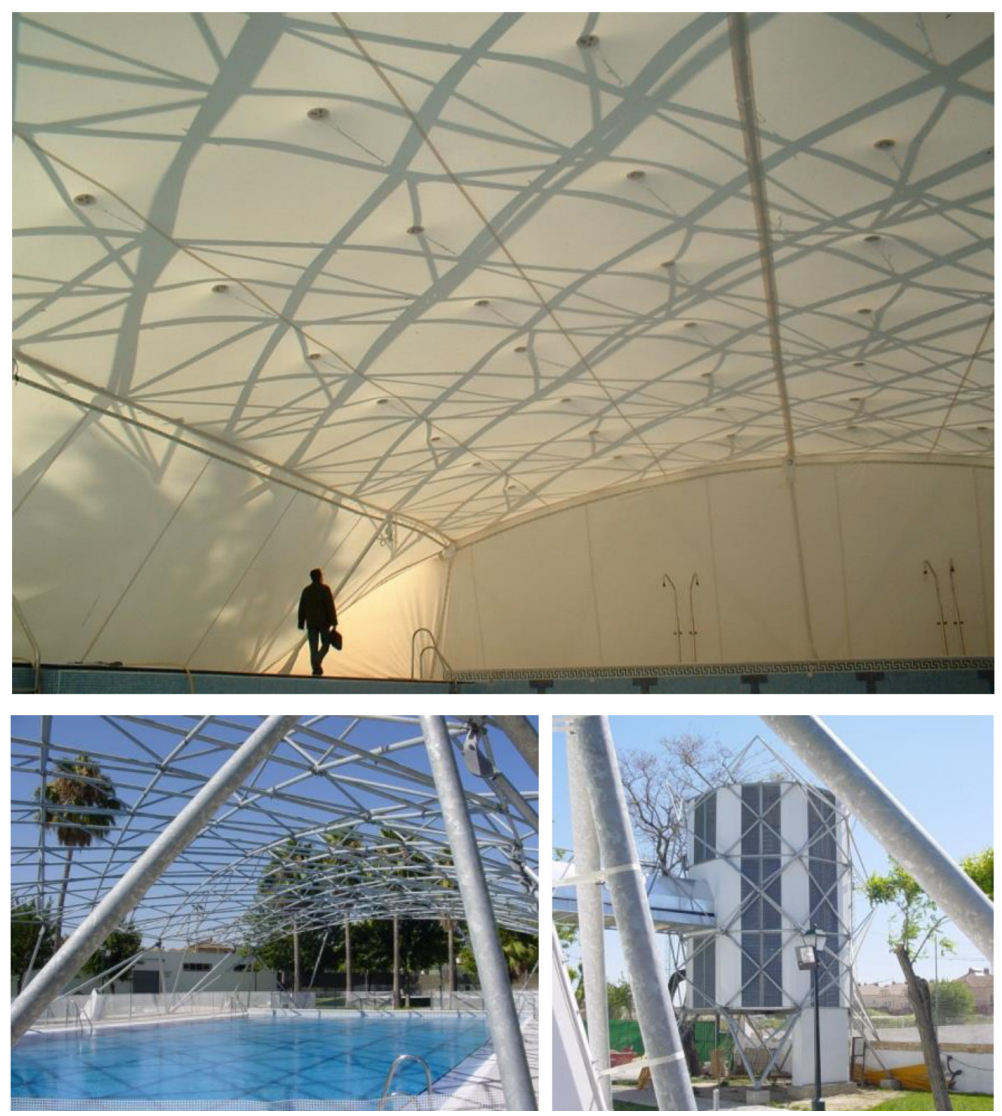

Figure 2: Pool in Gines (Sevilla). Main space and tower's facilities. 
gular modules, scissors and stiffening bars. The system is completed by mobile joints that allow the folding/unfolding of the structure as assembly/disassembly action, reducing assembly time on site and media and energy consumption for this process. A textile membrane envelope was used. It was anchored to the floor and tensioned from the cover so it generated a continue capsule which was prepared to heat/cool the air inside. Thus, it became a very lightweight set $\left(0.20 \mathrm{KN} / \mathrm{m}^{2}\right)$.

In 2004, the system without deployable joints was again used as a structure for the tower's facilities which serves the pool described above. This time, used joints, apart from joining the different elements of the mesh, allowed the support for the slabs of the lower floors. The system thus showed its potential to accommodate multiple configurations and situations and its ability for tall buildings. Currently, double sinclastic curvature meshes with double covering layer are being developed for conditioning archaeological sites. Passive conditioning strategies are being used for treating the trapped air between the two layers of the covering system [19].

\subsection{Frameworks with flexible coverings (tensioned membranes)}

As noted in section 2.1, the relationship between structure and envelope determines the final weight and, therefore, the lightness of the whole building. Taking into account climate conditions in southern Spain (which allow the use of very lightweight solutions) and direct contact with industry explained in section 2.2, several buildings based on framework system have been built. In these cases, the structure has been reduced to boundary elements and stiffening framing large tensioned membrane cloths for covering. This system allows to build our lightest buildings $\left(0.15-0.17 \mathrm{KN} / \mathrm{m}^{2}\right)$.

Basically, once defined the most optimal geometry and materiality, from parametric processes, serialization of elements is set, depending on the possibilities of transport and assembly, and the different types of joints that will allow quick assembly. All geometries use bows because of their high rigidity and ability to transfer actions to the contour with minimum material consumption. All the joints are based on bridles or hasps joints, according to the required compatibility with the covering elements. For the joints of the structure with the covering membrane, there must be provided procedures to introduce the necessary tension (and subsequent control) of membranes.

Since 2004, multiple solutions based on the above definition have been built, above all, buildings for equipments (services, recreational, cultural, etc.) which require large covered surfaces with flexible program. This group includes the following works in Spain (Fig. 3): Extension of a School in Bollullos (Seville), Multipurpose Center in Pilas (Seville), Gas Stations in Ronda (Malaga), Theatre in Gines (Seville), Restaurant in Ibiza (Balearic Islands) [12]. Within this group stands out for its lightness $\left(0.16 \mathrm{KN} / \mathrm{m}^{2}\right)$ a system developed for covering sport courts of $10.00 \times 20.00 \mathrm{~m}^{2}$ size (Fig. 4). It leads to end design strategies to get an extremely lightweight construction and reduce assembly time to 2 days.

\subsection{Frameworks/Meshes with rigid coverings}

When it comes to the design of residential, teaching or tertiary (offices and hotels) building, using conditions require more materiality in the envelope. In these cases, it is necessary to combine the mesh/framework with the size and shape of the panels, bringing the structure to a mesh or a framework according to the type of envelope that is going to be used.

The process followed in built projects has been using a single mesh that serves as structure and as a support (without adding new elements) for enclosure panels. By this way, very 

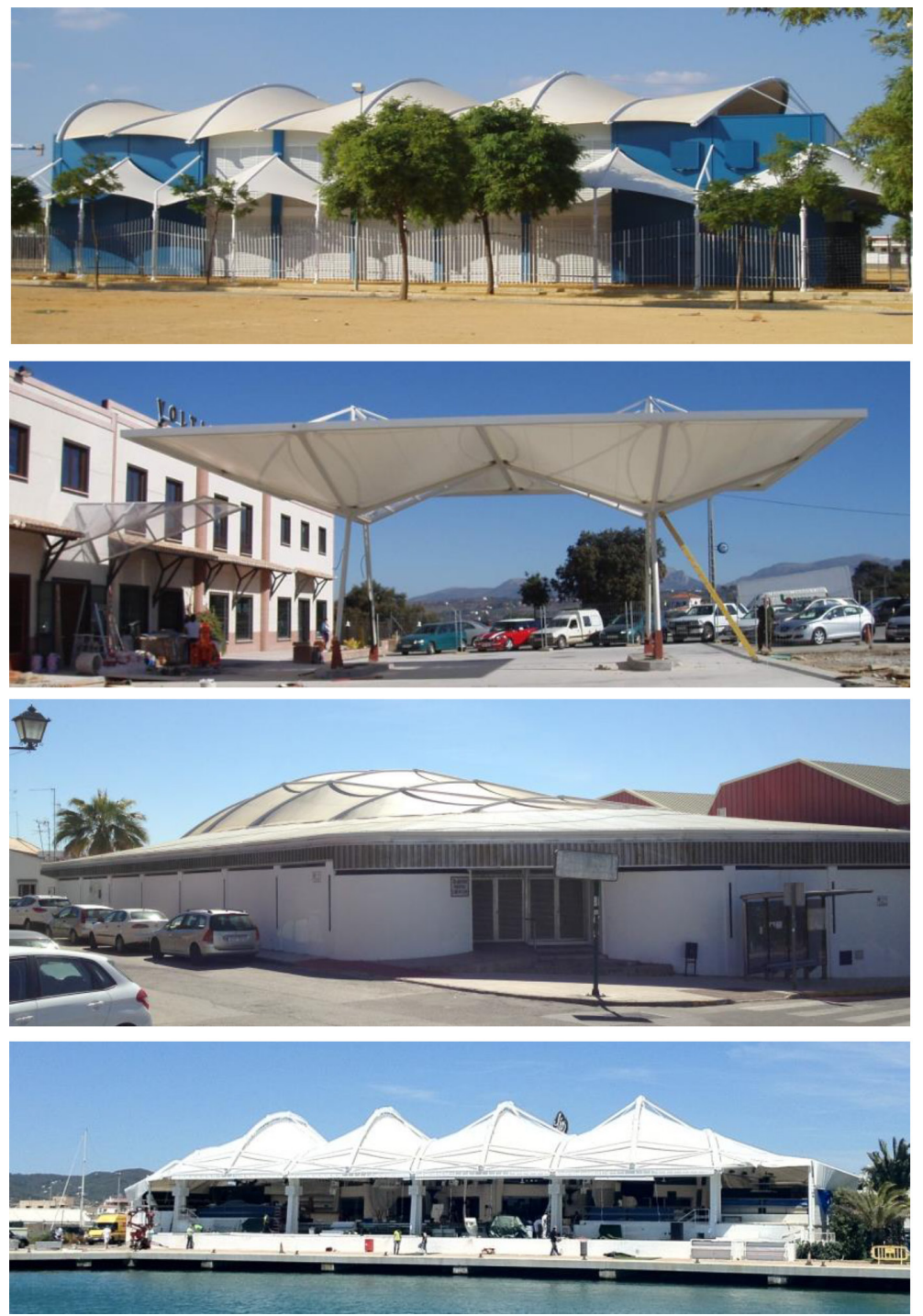

Figure 3: Frameworks with tensioned membranes.

lightweight elements are achieved. Once the geometry and final assembly materiality from parametric processes have been defined, we proceed to define at the workshop the maximum size of each of the already formed structure's modules and the type of joints that will come up.

Again, the lowest number of items to be transported and assembled on-site have been enhanced against others based on building the whole structure in situ, which have a high energy consumption increasing, therefore, their environmental impact. For the envelope, commercial panels are used (cellular polycarbonate sandwich insulating core steel, cement bonded particle board, timber, etc.) with predetermined characteristics, as appropriate. From 2007 to date, we have built several solutions that solve indoor pools, schools and houses 

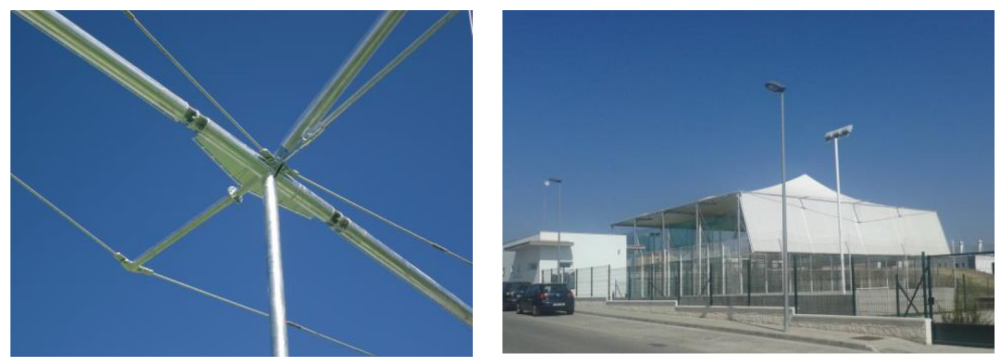

Figure 4: System for covering sport courts. Joints and external view.
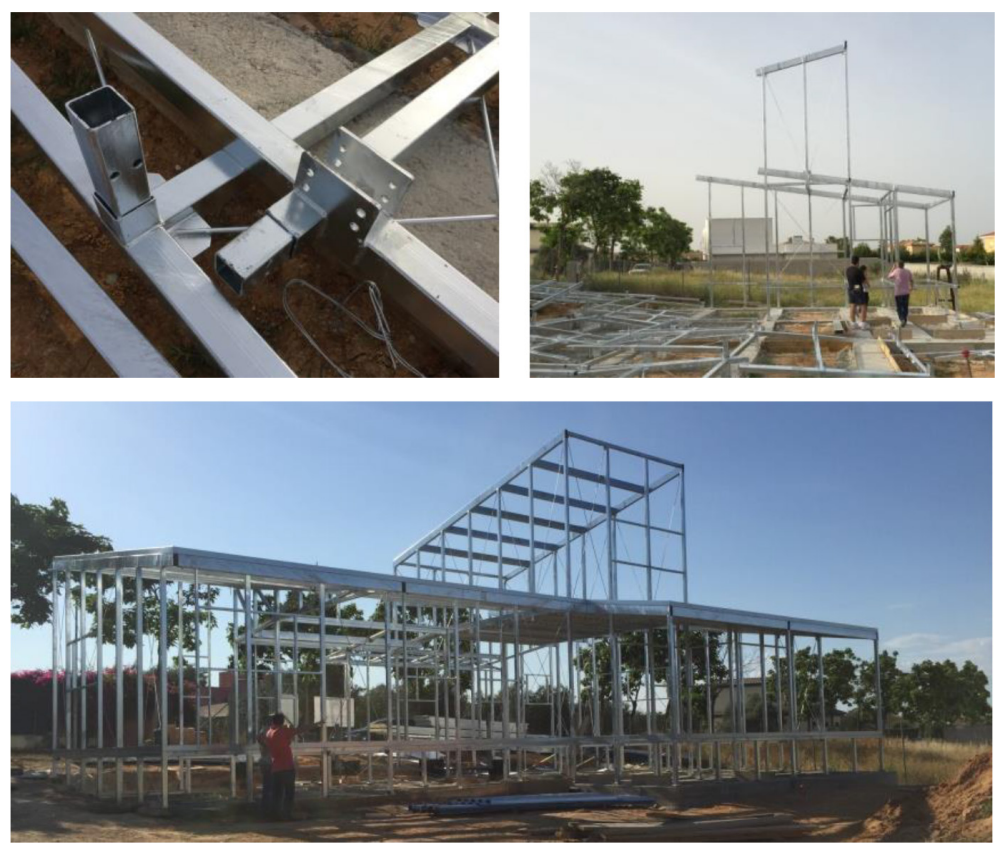

Figure 5: Mesh with rigid covering. Joints and structure.

(Fig. 5): Pool for a nursery in Gines (Seville), Nursery in Palomares (Seville) or House in Almensilla (Seville) [12].

\section{LIFE CYCLE ASSESSMENT OF LIGHTWEIGHT AND QUICK ASSEMBLY CONSTRUCTIONS. APPLICATION TO FLORIN SYSTEM}

As it was said in the introduction, this section will show the progress that has been done by our research team on the use of LCA as a tool for the design and optimization of lightweight construction and quick assembly models. The developed methodology that is indicated below has evolved from the works of Professor A. García Martínez and from several Degree Works made in the Master in Innovation in Architecture at the University of Seville, directed by Professors J.C. Gómez de Cózar and A. García Martínez. 
This paper presents the LCA of the structure of the pool in Gines (Seville), inaugurating a line of work which will be applied to other models in the future.

This analysis was carried out with the collaboration of Master students A. Mesa Gonzalez and M. Ruiz Alfonsea.

In order to value the construction/structural model of the Florin System, the deployable solution is compared with others which are on-site assembled (reinforced concrete structure, quick assembly aluminum structure and steel structure built on-site. Figure 6).

Life Cycle Assessment is a standardized method (ISO, 2006). It consists of four phases: scope and goal definition; life cycle inventory (LCI); life cycle impact assessment (LCIA) and the interpretation and results. The life cycle inventory is obtained from a graphic model and Ecoinvent Database [20]. The CML method and the Cumulative Energy Demand are used to assess the environmental impact. The study flows LCA "cradle to grave" methodology. In order to corroborate the building model proposed in the introduction, the following phases have been taken into account, according to the classification established in EN 15804 [21]: Phase 1: Production stage: includes the supply of raw materials (A1) and transport (A2); Phase 2: Treatment at workshop stage. includes manufacture of products and processes at workshop (A3); Phase 3: construction and disassembly stage: includes transportation from the factory to the site (A4), construction (A5), disassembly (C1) and transportation from the site to the recycling center $(\mathrm{C} 2)$; Phase 4 : End of Life stage: waste treatments $(\mathrm{C} 3)$ and discharge (C4).

According to ISO 14044, Life Cycle Impact Assessment (LCIA) is a way to evaluate the performance and environmental impact of a project based on a functional unit. Throughout this research, there is a focus on the assessment of Cumulative Energy Demand (CED) and Global Warming Potential (GWP) of the stage area construction [22].

Results are shown in Fig. 7. For the two analyzed categories (GWP \& CED), Florin System produces less than half impact than the second model which produces lower impact (alumi-
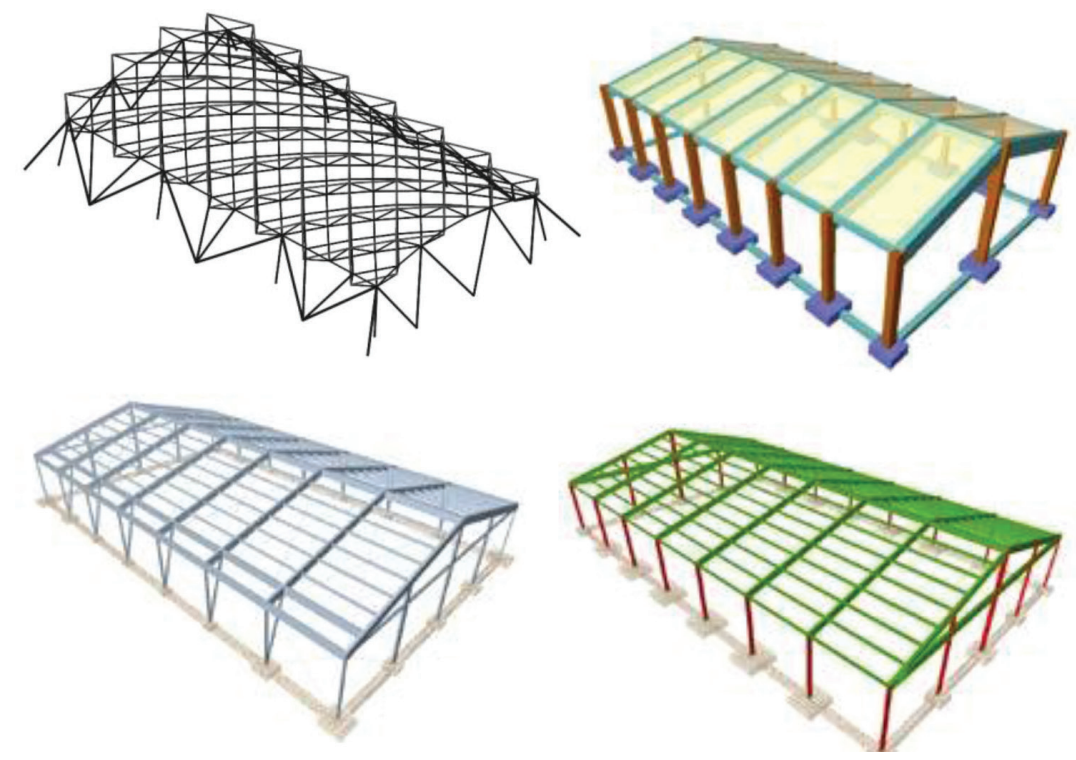

Figure 6: Geometry of 4 study cases. Case 1: Florin System, Case 2: Reinforced concrete structure, Case 3: Aluminium structure and Case 4: Steel structure built on-site. 


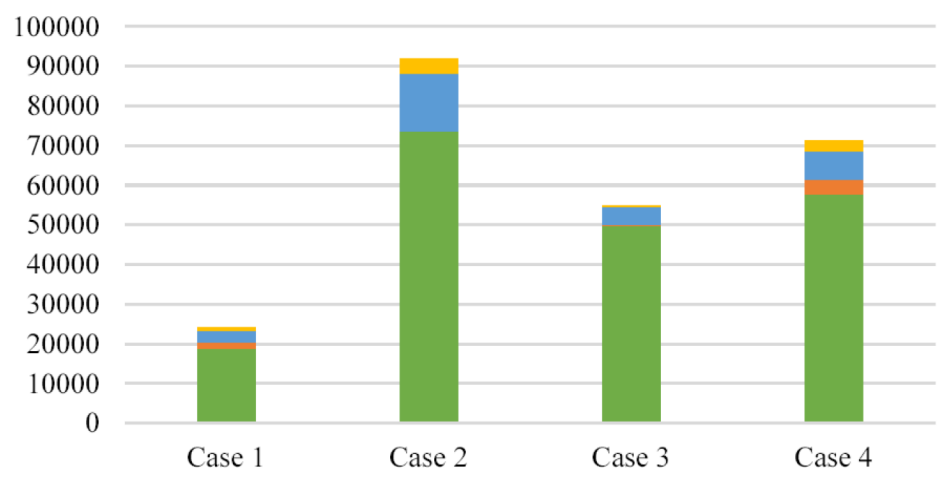

GWP (kgCo2-eq/m2)

\begin{tabular}{lcccc} 
& Case 1 & Case 2 & Case 3 & Case 4 \\
\hline Production & 18820.80 & 73723.19 & 49913.88 & 57763.15 \\
\hline Workshop & 1673.75 & 0.00 & 79.42 & 3623.73 \\
\hline Const./Disassem. & 2816.70 & 14567.18 & 4496.07 & 7280.05 \\
\hline End of Life & 904.93 & 3674.31 & 226.03 & 2616.72 \\
\hline Total & $\mathbf{2 4 2 1 6 . 1 9}$ & $\mathbf{9 1 9 6 4 . 6 8}$ & $\mathbf{5 4 7 1 5 . 4 0}$ & $\mathbf{7 1 2 8 3 . 6 5}$
\end{tabular}

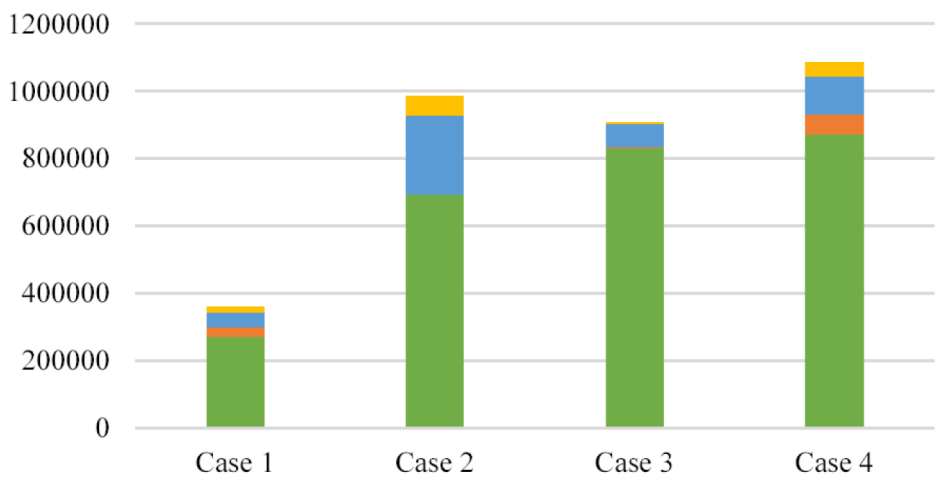

CED (MJ)

\begin{tabular}{lcccc} 
& Case 1 & Case 2 & Case 3 & Case 4 \\
\hline Production & 273035.84 & 695554.10 & 833642.54 & 872513.03 \\
\hline Workshop & 27562.23 & 0.00 & 1326.00 & 60495.30 \\
\hline Const./Disassem. & 44448.51 & 233405.49 & 68980.46 & 112793.44 \\
\hline End of Life & 13688.90 & 55581.60 & 4343.60 & 39583.05 \\
\hline Total & $\mathbf{3 5 8 7 3 5 . 4 8}$ & $\mathbf{9 8 4 5 4 1 . 2 0}$ & $\mathbf{9 0 8 2 9 2 . 6 1}$ & $\mathbf{1 0 8 5 3 8 4 . 8 1}$
\end{tabular}

Figure 7: Results, GWP and CED.

num case). So reducing the impact of different phases from the parameters entered in the proposed model (lightweight, quick assembly, reversibility and recycling) has taken effect.

If phase-to-phase results are analyzed, it can be seen that Case 1 model $\left(0.84 \mathrm{KN} / \mathrm{m}^{2}\right.$, including foundation) produces the least impact in Production phase.

This situation discards 2 and 4 cases which are much heavier $\left(7.87 \mathrm{KN} / \mathrm{m}^{2}\right.$ and $1.59 \mathrm{KN} / \mathrm{m}^{2}$ respectively). However, case 3 , lighter than all previous $\left(0.50 \mathrm{KN} / \mathrm{m}^{2}\right)$, produces in production stage an excessive impact in both categories due to the nature of its constituting material (aluminum), manifesting the importance of correctly choosing materials. 
In Workshop and Construction/Disassembly phases, in the two analyzed categories, case 1 values raise very similar to case 3 and lower than cases 2 and 4 . This situation shows that the deployability is a quick assembly process but when applied to structures of a certain size it requires a significant contribution of machinery that produces similar impact than quickly assembled systems (though slower) whose pieces are fastened with bolts (case 3).

In the End of Life phase, in both categories of impact, case 3 (aluminum) produces the least impact and its values are very close to case 1 and far away from cases 2 and 4 , like previous phases.

Thereby, results value the convenience of the proposed model against heavier and traditional assembly ones and, also, the possibility of using quick assembly frameworks/meshes against deployable systems because at construction/ demolition phases they can produce the same impact.

\section{CONCLUSIONS}

Using strategies for lightness leads to designing models for architecture which, with the right materials, reduce the environmental impact associated with production of elements against any type of heavy system.

Parameterization procedures, generated from embedded simulation software, allow to evolve to design processes, transforming them into open processes where each solution is unique and different, although manufacturing and assembly methods are the same.

As seen, when it comes to solutions for architecture, construction models with deployable meshes can evolve into models built with quick assembly frameworks, where the use of large format (flexible or rigid) elements for covering minimizes the presence of the structure and, therefore, the operations to manufacture and assemble it. This situation is evident in the LCA results where the values of cases 1 (Florin System) and 3 (quick assembly framework) are virtually the same when they are compared in Construction/Disassembly phases.

LCA is shown as an effective tool to optimize and guide the design of a solution from the proposed model.

For the analyzed case study, it is shown how associating of parameters between the building model (described in this paper's introduction) and the different phases of LCA leads to a considerable reduction in environmental impact against general or traditional models. It is, therefore, the most sustainable model.

For future contributions, as it has been indicated, it is being currently working in performing the LCA of all made works to further refine the building model and extend it to all kinds of architectural typologies. Similarly, work continues on the instrumental development of LCA from BIM tools.

\section{REFERENCES}

[1] Gómez de Cózar, J.C., Sistema para la construcción de estructuras estéreas de dos capas, desplegables, formadas por mallas de rombos y aspas multianguladas. Patente de invención. $\mathrm{N}^{\mathrm{o}}$ de publicación 2152787, Julio, 2001.

[2] García Diéguez, R. \& Gómez de Cózar, J.C., Florin system. Double layer spatial deployable structures. Proceeding of the IUTAM-IASS Symposiun, Cambridge, 1998.

[3] Gómez de Cózar, J.C., García Diéguez, R., System for the construction of double-layer deployable structures: processes of formal definition. Proceeding of the III International Conference on Mobile and Rapidly Assembled Structures, Madrid, 2000. 
[4] Akgun, Y. (aut.), Prof. Dr.-Ing. E.h. Werner Sobek \& Prof. Dr.-Ing. Balthasar Novak (dir.), A novel transformation model for deployable scissor- hinge structures. Universitat Stuttgart. Institut fur Leichtbau Entwerfen und Konstruieren. 2010.

[5] Buckminster Fuller, R., El capitán etéreo y otros escritos. Colección de arquitectura, 46. Colegio Oficial de Arquitectos Técnicos y Aparejadores de la Región de Murcia, 2003.

[6] Prouvé, J., Une architecture par l'industrie. Les Editions d'Architecture Artemis. Zurich, 1971.

[7] Arquitectura Viva 42. TECNÓFILOS. Foster, Grimshaw, Hopkins, Rogers: la tradición británica. V-VI 1995.

[8] Adalberth, K., Energy use during the life cycle of buildings: a method, Building and Environment, 32(4), pp. 317-320, 1997. https:/doi.org/10.1016/S0360-1323(96)00068-6

[9] García Martínez, A., Análisis del ciclo de vida (ACV) de edificios: propuesta metodológica para la elaboración de Declaraciones Ambientales de Viviendas en Andalucía, Universidad de Sevilla, 2010

[10] Gómez de Cózar, J.C. et al, Mallas y Entramados para la Arquitectura. Proc. of the II Jornadas de Investigación en Construcción. Madrid, 2008.

[11] Gómez de Cózar, J.C. \& Ariza López, I., Sistema Constructivo de Muro de Contención y de Carga Estanco Mediante Malla Estérea y Paneles Prefabricados. Patente de invención. No de publicación 2441123, Septiembre, 2014.

[12] Nd_Arquitectos, avaliable at: www.ndarquitectos.com.

[13] Gómez de Cózar, J.C., et al, Integration and balance: searching shapes. Proceeding of the International Conference on Textile Composites and Inflatable Structures, Stuttgart, Germany, 2009.

[14] Riley T., Light constructions the Museum of Modern Art, New York, 1995.

[15] Berchon, M. \& Bertier, L., La impresión, 3d. Gustavo Gili Eds., 2016.

[16] Friedman, Y., La arqitectura móvil. Poseidón S.L., 2013.

[17] Gómez de Cózar, J.C. (ed.), MIATD 2009-2010. Cuaderno 1_Fabricación de Modelos para la Arquitectura. Sevilla, 2011.

[18] Gómez de Cózar, J.C. et al, El Edificio Como Obra de Montaje: Fuentes y Herramientas. Proceeding of the II Jornadas Sobre Investigacion en Arquitectura y Urbanismo, Sant Cugat del Valles, Barcelona.

[19] Ordóñez Martín, M., Objetos arquitectónicos al servicio de la rehabilitación e interpretación del Patrimonio: Aspectos constructivos, movilidad y sostenibilidad. Aplicación a la cobertura temporal de yacimientos arqueológicos. Trabajo Fin de Master. Universidad de Sevilla. 2011.

[20] Ecoinvent, 2016, available at: http://www.ecoinvent.org/database/database.html.

[21] EN 15804:2012+A1:2014. Sustainability of construction works - Environmental product declarations - Core rules for the product category of construction products, CEN, Brussels, 2014.

[22] Galán Marín, C., Rivera Gómez, C. \& García Martínez, A., Use of natural-fiber biocomposites in construction versus traditional solutions: operational and embodied energy assessment. Materials, 9(6), 2016.

https:/doi.org/10.3390/ma9060465 